\title{
Organ protection during hypothermic circulatory arrest
}

Axel Haverich, MD

Christian Hagl, MD

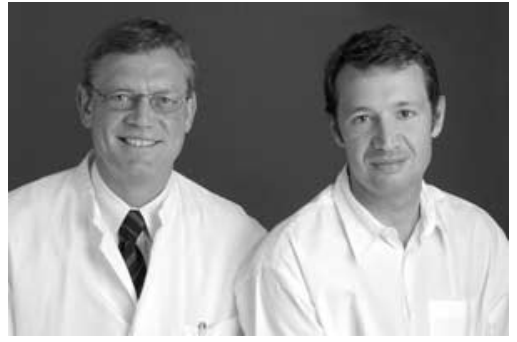

Haverich and Hagl

See related article on page 625 .
From the Klinik für Thorax-Herz-Gefässchirurgie, Medizinische Hochschule, Hannover, Germany.

Received for publication July 16, 2002; accepted for publication Aug 15, 2002.

Address for reprints: Axel Haverich, MD, Medizinische Hochschule Hannover, Klinik f. Thorax-, Herz- u. Gefässchirurgie, Hannover, Germany D-30623.

J Thorac Cardiovasc Surg 2003;125:460-2

Copyright $\odot 2003$ by The American Association for Thoracic Surgery

$0022-5223 / 2003 \$ 30.00+0$

doi: $10.1067 / \mathrm{mtc} .2003 .291$

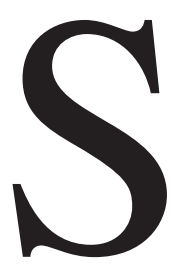

ince the first experimental studies by Bigelow and coworkers in the early 1950s, the use of hypothermic circulatory arrest (HCA) has become the standard technique for the surgical repair of certain congenital and acquired cardiovascular lesions. The outcome after these operations improved considerably over the past two decades and surgery requiring HCA can usually be performed with an acceptable risk for the patient. However, it is likely that these improvements are more a consequence of an increasing expertise with this type of surgery, rather than the influence of one particular organ protection method employed. Despite this fact, there is still room for improvement, since prolonged periods of HCA are still associated with significant morbidity and mortality.

\section{HCA and Multiorgan Dysfunction}

The rationale for the use of HCA during cardiopulmonary bypass is based on the reduction of the metabolic rate of the tissues and the subsequent increase of the tolerance to ischemia. As the brain is the organ most sensitive to ischemic damage, it is considered to be the limiting factor for the duration of HCA. Nevertheless, despite its protective effects, HCA can be detrimental for other organ systems. Cooper and coworkers, ${ }^{1}$ using a porcine model, were able to demonstrate that HCA was associated with endothelial dysfunction in the cerebral microvasculature as well as in large-caliber renal arteries and pulmonary veins. In addition, elevated liver and pancreatic serum enzyme levels can be clinically observed after prolonged periods of HCA (our own unpublished data). Not only HCA, but even cardiopulmonary bypass without HCA, is associated with significant physiologic alterations in the intestinal mucosal perfusion, epithelial permeability, edema formation, and blood flow regulation. In a multivariate analysis of 775 consecutive patients who underwent cardiac operations, HCA was a strong independent risk factor for postoperative renal impairment. ${ }^{2}$

On the basis of the idea that hypothermia may be protective for all tissues, profound cooling, as it is used clinically by the Mount Sinai group affiliated with Randall Griepp, is considered to be the most essential and critical factor for organ preservation. ${ }^{3}$ However, as has been mentioned before, deep hypothermia can cause significant side-effects (ie, coagulation disorders) and increases considerably the necessity for prolonged cardiopulmonary bypass time due to rewarming. As data accumulate, indicating that expanded periods of extracorporeal circulation are detrimental to the outcome, alternatives to profound hypothermia are needed to increase the tolerance to ischemia, reduce the necessity of prolonged HCA, or to decrease reperfusion injury after HCA.

\section{Selective Perfusion Techniques}

Clinically relevant perfusion-related concepts for single organ protection include the use of retrograde cerebral perfusion and, more recently, a revival of an old technique-selective antegrade cerebral perfusion. ${ }^{3-5}$ Since there is increasing evidence that nutritive function cannot be achieved via retrograde techniques, ${ }^{3}$ it seems that retrograde cerebral perfusion lost its popularity in favor of a more liberal use of selective antegrade cerebral perfusion. A detailed description and discussion concerning the different techniques has been published in another editorial in this Journal. $^{3}$ 


\section{Drug Interventions}

To increase the tolerance to ischemia, the use of potentially neuroprotective drugs is an appealing concept, especially since the circulatory arrest interval is well defined and allows a preischemic treatment. Therefore, it is evident that the use of these pharmaceuticals is more promising in HCA patients than for the postischemic treatment of patients after embolic strokes. Studies in a chronic porcine model showed that nontoxic drugs are available that have neuroprotective effects, making them potential candidates for clinical use. ${ }^{6}$ Additionally, combining drug treatment with selective perfusion techniques, to support adequate delivery of the agent into the target organ, seems to be a promising concept.

\section{Controlled Reperfusion}

The idea of avoiding reperfusion injury for single organ protection is well established and has been advocated by different investigators. Allen, Buckberg, and coworkers ${ }^{7}$ described in a piglet model in this issue of the Journal a new concept to avoid a "whole body reperfusion injury," offering an exciting opportunity to protect organs that have been subjected to prolonged periods of HCA. Accordingly, the compounds of the "reperfusate" have been chosen to prohibit what we know are important features of the reperfusion injury.

It is generally accepted that high concentrations of calcium can lead to an unphysiologic activation of proteases, kinases, phosphatases, and endonucleases and trigger detrimental cascades. Furthermore, cell calcium overload in combination with acidosis increases the production of reduced oxygen species, thus predisposing to free radicalrelated damage. ${ }^{8}$ Therefore, efforts were made to reduce the ionized calcium concentration, as well as the production of free radicals. Allen and coworkers ${ }^{7}$ used a combination of citrate, magnesium, and the indirect action of the sodium hydrogen ion exchange inhibitor HOE 642. Moreover, mannitol has been added to the reperfusate, not only to scavenge radicals, but to avoid edema formation, which is frequently seen after HCA. In this context, there is still confusion concerning the role of edema in the pathogenesis after HCA. It is known that cardiopulmonary bypass, as well as HCA, are associated with an overexpression of so-called acute phase reactants. Some of these can cause "capillary leak syndrome" with an extravasation of proteins and water across cellular membranes. Despite the obvious clinical observation of tissue edema in some of the patients after HCA, it is not known whether this is a cause rather than a reflection of tissue damage. Independent of the underlying pathophysiology, there is evidence from experimental data that even a slight increase of the intracranial pressureindicating cerebral edema-showed an inverse correlation with the outcome after HCA. ${ }^{9}$ In this context, we do not share the authors' opinion that $\mathrm{pH}$-stat is the ideal strategy for cooling, rewarming, and reperfusion. We agree that
pH-stat may have an advantage in achieving thorough cooling (by abolishing autoregulation), but we, like others, ${ }^{10}$ believe that the $\mathrm{pH}$-stat-induced cerebral vasodilation, causing "luxury perfusion" during rewarming, increases the risk for microembolization and macroembolization and actually aggravates tissue edema. On the basis of these considerations and the findings of Skaryak and coworkers, ${ }^{11}$ it seems logical to initiate cooling with $\mathrm{pH}$-stat, while rewarming should be performed under alpha-stat conditions. Since rewarming is probably the most crucial phase of the perfusion, and since cerebrovascular resistance, blood flow, and energy demand change continuously with the changes in temperature, slow warming should be performed, and the gradient between perfusate temperature and core temperature should never exceed $10^{\circ} \mathrm{C}$. In this context, it is interesting to note that even a short period of cold reperfusion can inhibit the rise in intracranial pressure, suggesting that initial cold reperfusion may decrease cerebral edema, thereby improving the outcome after prolonged HCA. ${ }^{12}$

Free radicals are highly reactive molecules implicated in the cause of ischemic tissue injury through a mechanism known as oxidative stress. The generation of these reactive oxygen and reactive nitrogen compounds has been shown to destroy cell membranes and to be detrimental for the survival of the cells. Studies in neuronal tissue showed an interaction between the formation of radicals and apoptotic cell death. Inasmuch as apoptosis is involved in the pathogenesis of tissue damage after HCA, ${ }^{13}$ avoiding hyperoxia and therefore reducing the formation of free radicals may reduce cell death after HCA.

Another approach in protecting organs from reperfusion injury is the depletion of leukocytes, based on the principle of the avoidance of a tissue infiltration with mononuclear cells. However, the discussion about the efficiency of leukocyte-depleting filters is controversial. Rimpilainen and coworkers, ${ }^{14}$ using a chronic porcine model, demonstrated that leukocyte depletion significantly improved brain protection during 75 minutes of $\mathrm{HCA}$ at $20^{\circ} \mathrm{C}$, whereas Langley and associates ${ }^{15}$ could not demonstrate a significant improvement in a less severe neonatal piglet model of 60 minutes of HCA at $18^{\circ} \mathrm{C}$. Since it has been demonstrated that cardiopulmonary bypass and circulatory arrest can trigger neutrophil adhesion to the endothelium and subsequent transmigration, techniques to avoid such an interaction seemed to be promising. Experimental data in small animals suggest that blocking the expression of endothelial adhesion molecules with specific antibodies has cell-protective effects.

In conclusion, the group affiliated with Gerald Buckberg introduced a fascinating new concept of "whole body protection" after HCA. Because of the current tendency to avoid general profound cooling and to rely on isolated cerebral perfusion, an adequate protection of the remaining 
ischemic organs, other than hypothermia, will be needed to avoid complications. The new approach demonstrated by the group from the University of California at Los Angeles offers the basis for further research in this important and exciting field.

\section{References}

1. Cooper WA, Duarte IG, Thourani VH, Nakamura M, Wang NP, Brown WM 3rd, et al. Hypothermic circulatory arrest causes multisystem vascular endothelial dysfunction and apoptosis. Ann Thorac Surg. 2000;69:696-702; discussion 703.

2. Zanardo G, Michielon P, Paccagnella A, Rosi P, Calo M, Salandin V, et al. Acute renal failure in the patient undergoing cardiac operation: prevalence, mortality rate, and main risk factors. J Thorac Cardiovasc Surg. 1994;107:1489-95.

3. Griepp RB. Cerebral protection during aortic arch surgery. J Thorac Cardiovasc Surg. 2001;121:425-7.

4. Kazui T, Washiyama N, Muhammad BA, Terada H, Yamashita K, Takinami M. Improved results of atherosclerotic arch aneurysm operations with a refined technique J Thorac Cardiovasc Surg. 2001; 121:491-9.

5. Bachet J, Guilmet D, Goudot B, Dreyfus GD, Delentdecker P, Brodaty D, et al. Antegrade cerebral perfusion with cold blood: a 13-year experience. Ann Thorac Surg. 1999;67:1874-8; discussion 1891-4.

6. Hagl C, Tatton NA, Weisz DJ, Zhang N, Spielvogel D, Shiang HH, et al. Cyclosporine A as a potential neuroprotective agent: a study of prolonged hypothermic circulatory arrest in a chronic porcine model. Eur J Cardiothorac Surg. 2001;19:756-64.

7. Allen BS, Veluz JS, Buckberg GD, Aeberhard E, Ignarro JL. Deep hypothermic circulatory arrest and global reperfusion injury: avoid- ance by making a pump prime reperfusate-a new concept. $J$ Thorac Cardiovasc Surg. 2003;125:625-32.

8. Siesjo BK, Zhao Q, Pahlmark K, Siesjo P, Katsura K, Folbergrova J. Glutamate, calcium, and free radicals as mediators of ischemic brain damage. Ann Thorac Surg. 1995;59:1316-20.

9. Hagl C, Khaladj N, Weisz DJ, Zhang N, Guo LJ, Bodian CA, et al. Impact of high intracranial pressure on neurophysiological recovery and behavior in a chronic porcine model of hypothermic circulatory arrest. Eur J Cardiothoracic Surg. 2002;22:510-6.

10. Ergin MA, Griepp EB, Lansman SL, Galla JD, Levy M, Griepp RB. Hypothermic circulatory arrest and other methods of cerebral protection during operations on the thoracic aorta. J Card Surg. 1994;9:52537.

11. Skaryak LA, Chai PJ, Kern FH, Greeley WJ, Ungerleider RM. Blood gas management and degree of cooling: effects on cerebral metabolism before and after circulatory arrest. J Thorac Cardiovasc Surg. 1995; 110:1649-57.

12. Ehrlich MP, McCullough J, Wolfe D, Zhang N, Shiang H, Weisz D, et al. Cerebral effects of cold reperfusion after hypothermic circulatory arrest. J Thorac Cardiovasc Surg. 2001;121:923-31.

13. Hagl C, Tatton NA, Khaladj N, Zhang N, Nandor S, Insolia S, et al. Involvement of apoptosis in neurological injury after hypothermic circulatory arrest: a new target for therapeutic intervention? Ann Thorac Surg. 2001;72:1457-64.

14. Rimpilainen J, Pokela M, Kiviluoma K, Anttila V, Vainionpaa V, Hirvonen $\mathrm{J}$, et al. Leukocyte filtration improves brain protection after a prolonged period of hypothermic circulatory arrest: a study in a chronic porcine model. J Thorac Cardiovasc Surg. 2000;120: 1131-41.

15. Langley SM, Chai PJ, Tsui SS, Jaggers JJ, Ungerleider RM. The effects of a leukocyte-depleting filter on cerebral and renal recovery after deep hypothermic circulatory arrest. J Thorac Cardiovasc Surg. 2000;119:1262-9. 